\title{
Principles of Conditioning Therapy and Cell Infusion
}

\author{
Sara Zulu and Michelle Kenyon
}

\begin{abstract}
Prior to haematopoietic stem cell transplant (HSCT), conditioning therapy is used for disease eradication, creation of space for engraftment and immunosuppression. Conditioning therapy includes combinations of chemotherapy, radiotherapy and/or immunotherapy. Chemotherapy is delivered in different phases: induction, consolidation and maintenance. Total body irradiation (TBI) is widely used as part of conditioning regimens preceding allogeneic HSCT and is able to target sanctuary sites where some drugs cannot reach. Cancer immunotherapy treatment harnesses the body's natural defences to fight the cancer, by involving components of the immune system. Conditioning therapy can have acute and chronic side effects due to the toxicity of the treatment. Nursing implications involve patient education and information, toxicity assessments, close monitoring and action plans. Stem cell infusion is usually a safe procedure but can cause adverse reactions ranging from flushing and nausea to life-threatening reactions. There should be written policies for the administration of cellular therapy products, and nurses must have training and competency in order to safely administer haematopoietic stem cells.
\end{abstract}

\section{Keywords}

Haematopoietic stem cell transplant - HSCT - Conditioning therapy Chemotherapy $\bullet$ Total body irradiation $\bullet$ TBI $\bullet$ Immunotherapy $\bullet$ Stem cell infusion

S. Zulu $(\bowtie)$

Cancer Services, Royal Free Hospital, London, UK e-mail: sara.zulu@nhs.net

\section{Kenyon}

Department of Haematological Medicine,

King's College Hospital NHS Foundation Trust, London, UK

\subsection{Conditioning}

Conditioning therapy in haematopoietic stem cell transplant (HSCT) is central to the preparation or 'conditioning' of the patient for the transplant. The three main goals of conditioning therapy are: 
Table 6.1 Examples of myeloablative, non-myeloablative and reduced intensity regimens

\begin{tabular}{l|l|l|}
\hline $\begin{array}{l}\text { Myeloablative } \\
\begin{array}{l}\text { Bu/Cy/Mel } \\
\text { (busulfan, cyclophosphamide, } \\
\text { melphalan) }\end{array}\end{array}$ & $\begin{array}{l}\text { Non-myeloablative } \\
\text { (fludarabine, cyclophosphamide, ATG) }\end{array}$ & $\begin{array}{l}\text { Flu/Bu } \\
\text { (fludarabine, busulfan) }\end{array}$ \\
\hline $\begin{array}{l}\text { TBI/TT/Cy } \\
\text { (TBI, thiotepa, cyclophosphamide) }\end{array}$ & $\begin{array}{l}\text { Flu/TBI } \\
\text { (fludarabine, TBI) }\end{array}$ & $\begin{array}{l}\text { Flu/Mel } \\
\text { (fludarabine, melphalan) }\end{array}$ \\
$\begin{array}{l}\text { Cy/VP/TBI } \\
\text { (cytarabine, etoposide, TBI) }\end{array}$ & $\begin{array}{l}\text { TLI/ATG } \\
\text { (total lymphoid irradiation, ATG) }\end{array}$ & $\begin{array}{l}\text { Flu/Cy } \\
\text { (fludarabine, cytarabine) }\end{array}$ \\
\hline
\end{tabular}

Adapted from EBMT-ESH Handbook

1. Eradication of disease

2. Creation of 'space' in the bone marrow for donor stem cells to engraft

3. Immunosuppression to decrease the risk of rejection of the donor cells by the host cells

Conditioning therapies include combinations of chemotherapy, radiotherapy and/or immunotherapy, using different regimens. The aim of conditioning regimens is to reduce relapse and rejection and can be fine-tuned to reduce treatment-related mortality. This can be done with 'reduced intensity' or non-myeloablative regimens which are less toxic or with myeloablative regimens which are a higher dose to wipe out or 'ablate' the marrow (see Table 6.1).

\subsection{Chemotherapy}

Dividing cells such as bone marrow stem cells proliferate and replicate in order to retain their function. Cytotoxic chemotherapy works by destroying rapidly dividing cells, including malignant cells. This is done by preventing the cells from dividing or by causing cell death (apoptosis) during different phases of the cell cycle.

The cell cycle comprises of five phases:

1. G0 phase-This is the resting phase which can last for months.

2. G1 phase-This is the growth phase, where RNA and protein synthesis occurs.

3. S phase-DNA is replicated so that when the cell divides, the new cell will have a copy of the genetic information. This phase lasts from 18 to $20 \mathrm{~h}$.
4. G2 phase-Further protein synthesis occurs preparing the cell for mitosis; this phase lasts from 2 to $10 \mathrm{~h}$.

5. M phase-The cell splits into two new cells. This phase lasts about 30-60 min.

There are three different means of classifying chemotherapy drugs: according to their cell cycle activity, their chemical groups or their mode of action. This chapter will focus on the mode of action classification, which is summarised in the table below.

\subsubsection{Combination Chemotherapy}

As previously mentioned all cells go through five phases during the reproduction cycle. Certain cytotoxic chemotherapy drugs work only at a specific phase of the cycle, whilst other drugs are not phase specific. In cytotoxic drug combination with synergy like pre-BMT conditioning (Table 6.2), it is logical to attack multiple phases of the cell replication cycle to prevent mutation and resistance from occurring. Combination chemotherapy allows for maximum cell kill, as each drug targets cells independently at different stages of the cell cycle. If the toxicities of the combination chemotherapy drugs do not replicate, the optimal dose could be administered without the high-grade toxicities.

\subsubsection{Cycles and Scheduling}

Chemotherapy is administered in cycles according to a schedule, in order to allow for recovery of the bone marrow and immune system after 
Table 6.2 Chemotherapy classifications according to their mode of action

\begin{tabular}{|l|l|l|}
\hline Cytotoxic classification & Mode of action & Examples \\
\hline Alkylating agents & $\begin{array}{l}\text { They prevent replication by substituting alkyl } \\
\text { groups for hydrogen atoms in cells. This causes } \\
\text { the DNA strands to break leading to mutation or } \\
\text { cell death }\end{array}$ & $\begin{array}{l}\text { Melphalan } \\
\text { Iphosphomide } \\
\text { Busulfan }\end{array}$ \\
\hline Antimetabolites & $\begin{array}{l}\text { These agents disrupt cellular metabolism } \\
\text { resulting in disrupted DNA and apoptosis. Act } \\
\text { in the S phase of the cell cycle }\end{array}$ & $\begin{array}{l}\text { Methotrexate } \\
\text { Cytarabine }\end{array}$ \\
\hline Fntitumor antibiotics & $\begin{array}{l}\text { They inhibit synthesis and replication by } \\
\text { binding to DNA and RNA }\end{array}$ & $\begin{array}{l}\text { Daunorubicin } \\
\text { Doxorubicin }\end{array}$ \\
\hline Plant alkaloids & $\begin{array}{l}\text { These are extracts from the pink periwinkle } \\
\text { plant. They bind to microtubular proteins } \\
\text { causing apoptosis acting mainly in the M phase }\end{array}$ & $\begin{array}{l}\text { Vincristine } \\
\text { Vinblastine }\end{array}$ \\
\hline $\begin{array}{l}\text { These agents are derived from the root of the } \\
\text { mandrake plant and act in the G2 and S phase } \\
\text { interfering with topoisomerase II enzyme } \\
\text { reaction }\end{array}$ & Etoposide \\
\hline $\begin{array}{l}\text { They cause lysis of lymphoid tumours. Act in } \\
\text { the G0 phase of the cell cycle }\end{array}$ & $\begin{array}{l}\text { Corticosteroids } \\
\text { Rituximab causes lysis of T- lymphocytes that } \\
\text { have the CD20 antigen on their cell surface. }\end{array}$ & Monoclonal antibodies (rituximab) \\
\hline Miscellaneous & &
\end{tabular}

Adapted from EBMT-ESH Handbook (2012)

administration (Brown and Cutler 2012; Grundy 2006). Malignant cells are expected to have a lengthier time to recover than normal cells. In this way, by scheduling the treatment, 'normal' cells can recover from toxicity, whilst the malignant cells will be reduced with continued cycles of treatment. Administration of chemotherapy in cycles allows for the possibility of a larger dose of drugs to be given over a short period of time.

In leukaemia and lymphoma treatment, chemotherapy is usually divided into different phases:

- Induction: The first aim of the treatment is to achieve remission. Chemotherapy is administered in order to eradicate the malignant cells.

- Consolidation (intensification): After remission is achieved, further treatment is given in order to prevent a recurrence of malignant cells. Consolidation chemotherapy can include radiotherapy or a stem cell transplant.

- Maintenance: Treatment is given in order to 'maintain' remission and prevent relapse. Maintenance treatment may include chemotherapy, hormone therapy or targeted therapy.

\subsubsection{Modes of Administration}

Cytotoxic therapy can be delivered via different routes. The four most used in HSCT are:

1. Intravenous (IV): This is the most common route of administration in HSCT. The drug is delivered directly into the blood stream via a cannula or a central venous access device. Risks to IV administration include extravasation and chemical phlebitis (chemical reaction to the vein causing hardening of the view or cording).

2. Subcutaneous: This is administered as an injection under the skin. Risks include irritation to the surrounding tissue, trauma (which could be due to low platelet count) or infection.

3. Oral: This route is usually self-administered. It is important that the patient is able to swallow, has sufficient manual dexterity and is compliant. Risks including vomiting after a given dose can reduce bioavailability.

4. Intrathecal (IT): This is administration by lumbar puncture into the cerebrospinal fluid to treat or prevent disease in the central nervous system (CNS). Intrathecal administration can be fatal if the incorrect type of cytotoxic agent 
is used, i.e. vinca alkaloids. National guidance has been publicised for the safe administration of IT chemotherapy.

\subsubsection{Side Effects and Nursing Implications}

- Chemotherapy side effects can be acute or chronic.

- Chemotherapy not only destroys malignant cells but also rapidly dividing 'normal' cells. The 'normal' cells that are most frequently affected include bone marrow cells, hair follicles, mucosal lining of the GI tract and skin, fertility and germinal cells.

- Nursing implications involve patient education and information, toxicity assessments, close monitoring and action plans.

- Chapters 9 and 10 discuss acute complications and supportive care in more detail.

\subsection{Radiotherapy}

Radiotherapy in HSCT is used as part of lymphoma treatment, as prophylaxis and treatment of disease and as palliative treatment for myeloma and lymphoma. Radiotherapy uses ionising radiation to control or kill malignant cells.

\subsubsection{Total Body Irradiation}

Total body irradiation (TBI) alongside high-dose chemotherapy helps to kill off leukaemia, lymphoma or myeloma cells in the bone marrow. This allows the patient to be in a preparation phase to receive the donor stem cells as part of the recovery stage of the treatment.

TBI is widely used as part of myeloablative, reduced intensity and non-myeloablative conditioning regimens preceding HSCT. As well as eradicating disease, immunosuppressive effect and creating space for donor cells to engraft; TBI is able to target sanctuary sites such as the CNS or gonads where some drugs cannot reach.

Most centres use a linear accelerator machine as a source of radiation. Patients are positioned either on their side or in a lateral position at a calculated distance from the machine. TBI is delivered in various doses and scheduling. The dose can be single (1-8 Gy total dose), fractionated (10-14 Gy total dose over 3 days) or hyperfractionated (14-15 Gy total dose over 4 days). As with chemotherapy scheduling, fractionated doses of TBI minimise toxicity (Apperly et al. 2012).

Some centres use lead shielding blocks to protect parts of the body such as the lungs and eyes; however, shielding organs could potentially shield leukaemic cells, so many centres opt not to do this.

\subsubsection{Side Effects and Nursing Implications}

Side effects of TBI can be acute or chronic. As TBI is usually given in combination with chemotherapy, it can be difficult to differentiate between the causes of the toxicities. Immediate side effects of TBI include bone marrow suppression, alopecia, nausea, vomiting, parotid swelling and erythema.

Chronic side effects of TBI include cataracts, infertility and interstitial pneumonitis. Nursing implications involve patient education and information, toxicity assessments, close monitoring and action plans (Apperly et al. 2012).

Chapters 9 and 10 discuss acute complications and supportive care in more detail.

\subsection{Immunotherapy}

The immune system has a natural ability to detect and destroy abnormal cells and in doing so prevents the development of many cancers.

However, cancer cells are sometimes able to avoid detection and destruction by the immune system by using a variety of strategies.

Cancer cells may:

- Reduce the expression of tumour antigens on their surface, making it harder for the immune system to see them

- Express proteins on their surface that inactivate or neutralise immune cells 
- Encourage cells in the surrounding environment to release substances that suppress immune responses and help to promote tumour cell growth and survival

\subsubsection{Cancer Immunotherapy}

This is a type of cancer treatment that is designed to harness the body's natural defences to fight the cancer by involving or using components of the immune system.

Some cancer immunotherapies consist of antibodies that bind to, and inhibit the function of, proteins expressed by cancer cells. Other cancer immunotherapies include vaccines and T-cell infusions.

A number of approaches are described briefly below.

\subsubsection{Immune Checkpoint Blockade}

Immune checkpoints are pathways embedded into the immune system that keep immune responses in check. They help to limit the strength and duration of immune responses and prevent strong responses that might damage normal as well as abnormal cells. Tumours appear to hijack certain immune checkpoint pathways and their proteins and use them to suppress normal immune responses.

This therapy targets the immune checkpoint pathways so that when the immune checkpoint proteins are blocked, the 'brakes' on the immune system are released and it behaves normally once again and destroys the cancer cells.

Immune checkpoint blockade with antibodies that target cytotoxic T-lymphocyte-associated antigen 4 (CTLA-4) and the programmed cell death protein 1 pathway (PD-1/PD-L1) has shown promising results in a variety of malignancies.

\subsubsection{Immune Cell Therapy}

Adoptive cell therapy (ACT) is a treatment that uses a cancer patient's own T cells. These cells are collected from the blood of the patient and then grown in the laboratory or expanded in vitro. These cells are activated by treatment with cytokines and then infused back to the patient.
An emerging form of ACT is chimaeric antigen receptor (CAR) T-cell therapy. A patient's T cells are collected from the blood and modified to express CAR protein. These cells are grown in the laboratory to produce large numbers of CAR $\mathrm{T}$ cells, which are then infused back into the patient.

In the blood, the CAR T cells bind to the cancer cells, become activated and attack and destroy them.

\subsubsection{Therapeutic Antibodies}

Therapeutic antibodies are 'drug'-based antibodies produced to destroy cancer cells.

One group of therapeutic antibodies is called antibody-drug conjugate (ADC). An antibody is connected to a toxic ingredient such as a drug, toxin or radioactive substance. When the antibody-drug conjugate (ADC) binds to the cancer cell, it is absorbed, and the toxic substance is released killing the cell.

Not all therapeutic antibodies are connected to toxic substances. Some antibodies cause cancer cells to commit suicide (apoptosis), and others can make the cancer cells more recognisable to certain immune cells (complement) and help to facilitate cell death.

\subsubsection{Therapeutic Cancer Vaccines}

Another approach to immunotherapy is the use of cancer vaccines. These vaccines are usually made from a patient's own cancer cells or from substances produced by cancer cells. It is intended that when a vaccine containing cancerspecific antigens is injected into a patient, these antigens will stimulate the immune system to attack cancer cells without causing harm to normal cells.

\section{Further Reading}

http://www.nature.com/

Search on:

Cancer Reviews. Immunology Reviews. 


\subsection{Paediatric Considerations}

\section{Conditioning}

There are differences between adult and paediatric patient's conditioning. Children can generally tolerate side effects better than adults, and higher doses may be used. On the other hand, conditioning regimens affect growth and endocrine development of the child.

Studies so far indicate that reduced intensity conditioning (RIC) in haematopoietic cell transplantation may have an important role in treating children with primary immune deficiencies: such regimens can be used without severe toxicity in patients with pre-transplant infections or severe pulmonary or hepatic disease. RIC has extended the role of allogeneic transplantation to many patients who until recently were considered ineligible for this procedure (Chiesa and Veys 2014).

Disease-specific treatment protocols can be found, for example, in the EBMT Handbook 2012, Chap. 20. Chemotherapy and radiation therapy side effects will be discussed in more detail in Chap. 8 .

\subsubsection{Chemotherapy}

Children in general tolerate side effect better than adults, so higher total doses may be used (Satwani et al. 2008).

When treating paediatric patients' prescriptions should be made by body surface area (BSA) $\mathrm{mg} / \mathrm{m}^{2}$ or $\mathrm{mg} / \mathrm{kg}$ using recent weight and height.

\subsubsection{Total Body Irradiation}

TBI has severe side effects when administered to children and adolescents, and it should be avoided, whenever possible. The risk for secondary malignancies is significantly higher compared to pharmacological conditioning (ALL). Most teams use conditioning regimens (AML) that do not involve TBI (EBMT Handbook 2012).

When TBI is used, it is commonly given in fractions (two doses per day) to minimise the side effects.

Paediatric patients need age-appropriate preparation for radiotherapy. This can be done by the play therapist, but if there is no such pro- fessional, it should be done by a nurse. Preparations should be started well in advance to allow the patient and parents ask questions. It is possible to listen to music or fairy tales whilst having TBI. Immobilisation is a prerequisite for accurate radiotherapy, so anaesthesia is required for younger children.

\subsection{Stem Cell Infusion}

Haematopoietic stem cells (HSCs) can be procured from the patient (autologous) or from a donor (allogeneic or cord blood).

HSCs procured from the patient are almost always sourced from peripheral blood during apheresis (see Chap. 5).

HSCs procured from a donor can be sourced from the peripheral blood (apheresis), bone marrow or umbilical cord.

After harvesting, HSCs can be stored using cryopreservation. Dimethyl sulfoxide (DMSO) is a common cryopreservative used in the storage of HSCs.

\subsubsection{Adverse Reactions}

An adverse reaction is a noxious and unintended response suspected or demonstrated to be caused by the collection or infusion of a cellular therapy product or by the product itself.

The stem cell infusion is a generally safe procedure, but it can cause a variety of adverse reactions ranging from flushing and nausea to life-threatening reactions. It is imperative that the healthcare team is trained for early identification and managing of possible adverse reactions. Nurses must obtain baseline vital signs including temperature, breath sounds, pulse oximetry, weight and fluid status prior to the cell infusion.

Possible adverse reactions are:

\section{Fresh stem cells}

Allergic reaction

Haematolytic transfusion reaction

Fluid overload

Micropulmonary emboli

Infection 


\section{Preserved stem cells}

Bad taste in the mouth, nausea and vomiting (DMSO)

Arrhythmia hypertension

Haemoglobinuria

Allergic reaction

Haemolytic transfusion reaction

Fluid overload

Micropulmonary emboli

Infection (Costa et al. 2014; Tomlinson and Kline

2010; Truong et al. 2016; Vidula et al. 2015)

\subsubsection{Nursing Care: Pre-, During and Post Stem Cell Infusion}

\subsubsection{Pre-infusion Assessment}

Maintain a safe environment Ensure that your patient is prepared and the room is organised out in a way that you have access to the patient and you have access to everything you need including oxygen and suction. The patient should be nursed on a bed during the stem cell infusion, in case of severe allergic reaction.

Baseline observations Record baseline observations in order to assess the patient's physiological status during and post infusion.

Preparing patient for transfusion If patients are receiving cells previously cryopreserved with DMSO, they should receive a premedication with antihistamine, corticosteroids, antipyretics and anti-emetics. The nurse should discuss the procedure including length of time, how they may feel and what to tell the nurse if they experience any of the common side effects. Encourage your patient to tell you how they feel during the entire procedure, to ensure adverse incidents are spotted, to offer reassurance or to ensure side effects are managed.

IV line care Check the IV line for patency. On the whole, patients undertaking a stem cell infusion will have a permanent, central line in situ. Common lines used for this treatment are PICC lines and Hickman lines. Ensure aseptic non-touch technique is used to prevent the risk of infection.

Toileting Discuss with the patient and encourage toileting prior to starting the procedure in order to minimise interruption to the stem cell infusion and also ensure safety for the patient.

Psychological support Day zero can be a momentous occasion for someone who requires a stem cell transplantation. Patients may experience a range of emotions, from elation through to distress, anxiety, vulnerability and helplessness. Using simple techniques such as discussing the procedure, and listening and offering reassurance may help to reduce patients anxiety.

\subsubsection{During Stem Cell Infusion}

IV line care Ensure aseptic non-touch technique is used to prevent the risk of infection.

Physiological monitoring Should be carried out at least every 10-15 min and increased if there are any concerns with the patients' condition during the infusion. $\mathrm{O}_{2}$ saturations are monitored constantly during infusion. Treat problems as they arise (i.e. drop in saturations, give $\mathrm{O}_{2}$ as prescribed).

Assess for potential side effects Patients can have mild to severe reactions to a stem cell infusion. Autologous stem cells tend to be cryopreserved. Patients can experience allergic reactions including nausea, flushing, rash, chest tightness, shortness of breath and chills. For anaphylaxis, follow your centre guidelines for managing an anaphylaxis event. For other side effects, the infusion can be slowed down according to how the patient tolerates the infusion. Reassure the patient and treat the side effects as they occur.

\subsubsection{Post Stem Cell Infusion}

Physiological monitoring Assess for later effects of the cell infusion. Observations should be performed half hourly for the next $2 \mathrm{~h}$, then hourly for another $2 \mathrm{~h}$, and four hourly thereafter.

Documentation Document the care event in patients' medical records, and complete the cell infusion record.

\subsubsection{JACIE Standards}

The JACIE process has been explained in detail in Chap. 1. JACIE Standards give instruction 
on how to safely administer the product. Nurses must have training and competency for administration of cellular therapy products. There shall be also written policies for administration of cellular therapy products (JACIE Standards B3.7).

There shall be a policy addressing safe administration of cellular therapy products. These policies should determine the appropriate volume and dose of red cells, cryoprotectants and other additives and volume of ABO-incompatible red cells in allogeneic cellular therapy products. Two qualified persons shall verify the identity of the recipient, the product and the order for administration (JACIE standards B7.6).

For more detailed information, please visit the www.jacie.org

\section{References}

Apperly J, Carreras E, Gluckman E, Masszi T, The EBMT handbook. 6th ed. Paris: European School of Haematology; 2012.

Brown M, Cutler T. Haematology nursing. Hoboken, NJ: Wiley-Blackwell. 2012.

Chiesa R, Veys P. Reduced-intensity conditioning for allogeneic stem cell transplant in primary immune deficiencies. Expert Rev Clin Immunol. 8:255-67. Published online: 10 Jan 2014. Download citation https://doi.org/10.1586/eci.12.9
Costa Bezerra Freire N, et al. Adverse reactions related to hematopoietic stem cell infusion. J Nursing UFPE Online. 9:391-8.

FACT-JACIE international standards for hematopoietic cellular therapy, 6th ed. 2015.; www.jacie.org

Grundy M. Nursing in haematological oncology. 2nd ed. Edinburgh: Ballière Tindall; 2006.

Mulay SB, et al. Infusion technique of hematopoietic progenitor cells and related adverse events. Transfusion. 2014;54:1997-2003.

Satwani P, Cooper N, Rao K, et al. Reduced intensity conditioning and allogeneic stem cell transplantation in childhood malignant and non-malignant diseases. Bone Marrow Transplant. 2008;46:173-82.

Tomlinson D, Kline NE, editors. Pediatric oncology nursing: advanced clinical handbook. 2nd ed. New York/ Dordrecht/Heildelberg: Springer; 2010.

Truong TH, Moorjani R, Dewey D, Guilcher GMT, Prokopishyn NL, Lewis VA. Adverse reactions during stem cell infusion in children treated with autologous and allogeneic stem cell transplantation. Bone Marrow Transplant. 2016;51:680-6.

Vidula N, et al. Adverse events during hematopoietic stem cell infusion: analysis of the infusion product. Clinical Lymphoma, Myeloma And Leukaemia. 2015;15:e157-62.

\section{Further Reading}

Pan London Guidelines for the Safe Prescribing, Handling and Administration of Systemic Anti Cancer Treatment Drugs. www.londoncanceralliance.nhs.uk.

Good practice guide for pediatric radiotherapy, Children's cancer and leukaemia group, Society and college of radiographers, The Royal College of Radiologists, 2012.

Open Access This chapter is licensed under the terms of the Creative Commons Attribution 4.0 International License (http://creativecommons.org/licenses/by/4.0/), which permits use, sharing, adaptation, distribution and reproduction in any medium or format, as long as you give appropriate credit to the original author(s) and the source, provide a link to the Creative Commons license and indicate if changes were made.

The images or other third party material in this chapter are included in the chapter's Creative Commons license, unless indicated otherwise in a credit line to the material. If material is not included in the chapter's Creative Commons license and your intended use is not permitted by statutory regulation or exceeds the permitted use, you will need to obtain permission directly from the copyright holder. 